\title{
Mulheres viris, mulheres monstruosas: Apontamentos sobre o romance Luzia-Homem
}

\author{
Márcia Maria de Medeiros* \\ Tânia Regina Zimmermann*
}

Resumo: A figura da mulher viril assola a imaginação da humanidade desde o mundo grego, quando das primeiras narrativas sobre as amazonas, que se referem ao culto arcaico relacionado com a Deusa Mãe, atestada em sociedades matriarcais e marginalizados no patriarcado. Em LuziaHomem, romance de Domingos Olímpio, a personagem central do livro apresenta características familiares para este grupo de mulheres, sendo representada como uma configuração do monstruoso, culminando em sua morte. Este artigo irá examinar as ligações entre o processo de construção da idéia de virilidade e monstruosidade intrínseco, quando a figura masculina é uma mulher e não um homem.

Palavras-chave: mulher; monstro; Luzia-Homem; gênero; literatura brasileira.

Abstract: The figure of the woman manly plagues the imagination of mankind since the Greek world when the first tales of the Amazonas, which refer to the archaic cult associated with the Mother Goddess attested in matriarchal societies and marginalized in patriarchy. In Luzia-Man, romance from Domingos Olímpio, the central character of the book presents household characteristics for this group of women being represented as a configuration of the monstrous, culminating in her death. This article will examine the links between the process of building the idea of virility and its intrinsic monstrosity, when the male figure is a woman and not a man. Keywords: woman; monster; Luzia-Homem; gender; brazilian literature.

\footnotetext{
* Doutora em Letras pela Universidade Estadual de Londrina. Professora adjunta do curso de Turismo Ênfase em Ambientes Naturais da Universidade Estadual de Mato Grosso do Sul (UEMS), unidade universitária de Dourados e do Programa de Mestrado em Letras da UEMS, unidade universitária de Campo Grande.

* Doutora em História pela Universidade Federal de Santa Catarina (UFSC) e pós-doutoranda pela Universidade Federal do Paraná. Professora adjunta do curso de História da Universidade Estadual de Mato Grosso do Sul, unidade universitária de Amambaí e do programa de mestrado em Educação.
} 
Quando se trata sobre a temática das chamadas "mulheres viris"" tem-se em mãos um tema rico, porém pleno de possibilidades de equívoco, podendo descambar a sua abordagem para a polêmica ou mesmo para a vulgaridade. Essa questão é conhecida de muitas culturas, bastando para confirmar esse fato citar no mundo ocidental duas das mais importantes a referendar a mesma: a grega através do mito das Amazonas e a nórdica, que o demonstra a partir das suas Valquírias. Segundo Pierre Brunel, na obra Dicionário de Mitos Literários: "Ambas tem a vantagem de ligar-se diretamente ao mito [das mulheres viris] e podem resumir muito bem os aspectos essenciais do assunto". (BRUNEL, 2000: 744)

Sendo assim, faz-se necessário observar alguns elementos inerentes a tais construções para que se possa entender como a personagem Luzia, do romance de Domingos Olympio, Luzia-Homem, se enquadra nessa perspectiva e de que maneira ela é construída a partir da ótica do monstruoso e da monstruosidade se fazendo, ao final da obra, necessária a sua destruição.

A aproximação entre a História e Literatura oferece ao historiador uma parceria para a inventiva narrativa do passado. Para Durval Muniz, não é preciso temer a narrativa literária, pois podemos caminhar com ela. (DURVAL MUNIZ, 2007). Ao alargar o entendimento sobre as fontes históricas ganhamos as páginas literárias e delas podemos ampliar as análises em torno de sensibilidades, de vivências pessoais e coletivas que dificilmente de outro modo nos chegaria à compreensão de alguns processos históricos. Uma abordagem a partir destas observações poderia reconstruir alguns sistemas de representação como os que aqui propusemos em relação as relações de gênero no romance Luzia-Homem.

Ao nos referirmos às relações de gênero partimos primeiramente das diferenças culturais entre mulheres e homens. Porém, tal assertiva direcionou o foco para o que caracteriza e justifica a desigualdade e com isso dificultou o entendimento das relações sociais de gênero e da historicidade do sexo. Por isso, seguimos o trabalho de Joan Scott (1990), no qual o gênero se refere a uma construção histórica das relações de poder entre homens e mulheres, e deve contemplar definições plurais de gênero, assim como de masculinidade e feminilidade. Logo, os estudos de gênero e os conceitos correlatos variaram ao longo da história. Por isso, Scott acentua que gênero refere-se às relações sociais nas quais indivíduos e grupos atuam (1990).

\footnotetext{
${ }^{1}$ Esse epíteto é fornecido por Pierre Brunel no verbete de mesmo nome, na obra Dicionário de Mitos Literários. 
Em alguns estudos de gênero as distinções e a interação entre sexo e gênero ou entre biologia e cultura não são claras. Tentativas neste sentido foram feitas por Thomas Laqueur (2001) e Judith Butler (2003). Ambos não definem os limites da biologia e da cultura, mas apontam que estes limites também podem variar nos processos históricos. Importa observar aqui que as distinções de gênero poderiam ser postas sob a perspectiva da monstruosidade e diante destas dificuldades leva-se em consideração que gênero será uma questão inconstante e contextual porque denota segundo Butler "mas um ponto relativo de convergência entre conjuntos específicos de relações, cultural e historicamente convergentes" (2003: 29).

Estas discussões conceituais e seus processos históricos são reveladores de que o corpo molda e é moldado pela identidade de gênero a qual é marcada pelas noções dominantes de feminilidade e de masculinidade. Ao nominar estas construções nosso romance pauta-se novamente naquilo que a linguagem comum considera o gênero, ou seja, no domínio da natureza, e, neste estudo volta-se a monstruosidade. Talvez por isso, que os estudos de gênero insistem em desnaturalizar estas construções, nas quais as oposições também foram construídas sobre os corpos sexuados produzindo novas desigualdades.

\section{A monstruosidade}

Segundo os gregos ${ }^{2}$, em algum lugar nos confins do mundo conhecido teria existido um lugar habitado por mulheres guerreiras cuja presença remontaria a épocas remotas. Essas mulheres seriam ancestrais dos Saurômatas ${ }^{3}$, e seu território teria sido o Ponto Euxino ${ }^{4}$. Na opinião de Pierre Brunel é difícil saber se esses autores gregos não pretendiam “(...) evocar, a título de vagas reminiscências, o culto arcaico da Deusa-Mãe, universalmente atestado, e uma leitura rápida ou uma informação com lacunas podem facilmente fazer do matriarcado um governo de mulheres!” (BRUNEL, 2000: 744)

Se o estudioso ou estudiosa se debruça sobre o mito a partir da premissa dos autores gregos percebe a existência de três aspectos do mesmo que ficaram enraizados no inconsciente coletivo ${ }^{5}$ até o mundo contemporâneo. Em um primeiro momento, as Amazonas

\footnotetext{
${ }^{2}$ Entre as autoridades gregas que falam sobre o assunto encontram-se Tácito, Plutarco e Heródoto.

${ }^{3}$ Povo que Jasão havia se comprometido a conquistar descendiam de um grupo de Amazonas que foram capturadas por Hércules durante seu nono trabalho. Sobre o assunto ver: GRAVES, Robert. O Grande Livro dos Mitos Gregos. São Paulo: Ediouro, 2008.

${ }^{4}$ Antiga província romana situada ao norte da região da Ásia Menor de mesmo nome, ao longo do Mar Negro.

${ }^{5}$ Essa categoria é utilizada neste artigo a partir da premissa de Jung, a qual considera que esse estrato é constituído pelos materiais que foram herdados, e nele é que residem os traços funcionais comuns a todos os
} 
eram "bárbaras", no sentido que os gregos usavam para significar essa palavra: elas não conheciam o que se constitui na qualidade mais importante da polis, que é o respeito às leis. $\mathrm{Na}$ verdade, elas eram transgressoras, elas rompiam as leis e os paradigmas que eram criados em relação a elas.

Ademais, desconheciam princípios como a navegação, por exemplo, conforme aufere Graves, na citação que segue: (...) elas romperam seus grilhões, mas, como nada sabiam de navegação, elas chegaram à deriva até o Bósforo, onde desembarcaram em Cremni, o país dos citas livres. (GRAVES, 2008: 688). Então, pode-se auferir que elas fogem a um padrão tido como ideal de civilização. Embora Elias e Scotson discutam outro contexto histórico observase que a esse ideal pode ser entendido como a construção de controles das pulsões emocionais, físicas e costumes, sendo que o conceito ainda poderia se referir a fatos políticos, sociais e econômicos. ${ }^{6}$

Esses discursos civilizatórios relacionados ao gênero implicavam na imposição de controles externos e internos em relação a manifestações emocionais, inclusive irrupções de violência. Observa-se que estes controles e formas de violência deveriam incidir, sobretudo sobre o corpo das mulheres. As mulheres guerreiras e conhecedoras de técnicas de navegação representavam uma ameaça à ordem preterida pelo mundo masculino. Na escritura deste texto concordamos com Dhoquais ao afirmar que "A mulher passa a ser uma espécie de base sobre a qual se assenta a paz social." ${ }^{, 7}$ As diferentes possibilidades de ações para as mulheres que não o casamento e a família implicavam em um pulular de imagens masculinas sobre as mesmas, às vezes de admiração e ou de depreciação destas ações, as quais deveriam ser combatidas.

A maioria dos comentaristas gregos que falam sobre elas constroem a mesma imagem: guerreiras que combatem a cavalo e que se utilizam do arco como arma; e para melhor manejá-lo elas queimavam o seio direito, advindo daí seu nome de Amazonas (do grego amazôn, ou sem seio). Em geral essas mulheres são apresentadas como filhas de Ares, o grande deus grego da guerra, belicosas em seu comportamento e inimigas do homem e do casamento.

seres humanos. Ela pode ser também entendida como um arcabouço de arquétipos cuja influência se expandem para além das margens da psique humana.

${ }^{6}$ ELIAS, Norbert. Über den Prozeß der Zivilization. Soziogenetische und psychogenetische Untersuchungen. Bd. 1: Wandlungen des Verhaltens in den weltlichen Oberschichten des Abendlandes. 20 Aufl. Frankfurt am Main: Suhrkamp, 1997, p. 89.

${ }^{7}$ DHOQUAIS, R. O Direito do Trabalho e o corpo da mulher (França: séculos XIX e XX). In: MATOS, Maria Izilda S. de; SOIHET, Rachel. O Corpo Feminino em Debate. São Paulo: UNESP, 2003, p. 47. 
Em segundo lugar, de acordo com os textos gregos as Amazonas seriam verdadeiras mulheres-homens, a um só tempo suas iguais e suas inimigas. Faz parte da formação do jovem guerreiro, que anseia por colocar seu valor a prova, empreender expedições contra elas e, de preferência, exterminá-las. É o que se percebe no trecho abaixo transcrito da Odisseia, de Homero:

Pois o queres, conhece-me a linhagem;/ É bem sabida. - Num recesso de Argos,/ A corcéis A corcéis pacigosa, avulta Efira,/ Onde Sísifo Eólides, o astuto/ Mais cadimo reinou; seu filho Glauco/ Teve a Belerofonte, a quem prendaram/ Os Céus de esforço e garbo e gênio afável./ Mas de Preto a mulher, a diva Anteia,/ Louca de amores, desejou furtiva/ Misturar-se com ele, e despeitosa/ De não ter seduzido o casto peito/ Pérfida ao rei mentiu: Belerofonte/ Intentou-me forçar; ou morre ou mata-o —,/ Em sanha Preto, a cujo prepotente/ Cetro os Aquivos sujeitara Jove,/ O exilou da cidade; e, religioso/ Temendo assassiná-lo, urdiu na mente/ Feia vingança: de funestas cifras/ Ao sogro o envia com fechado rolo,/ Onde a sentença lhe traçou de morte./ Por numes escoltado, ao Xanto e à Lícia/ Plaga admitido, em novenal hospício/ Lhe imolou touros nove o rei benigno;/ Mas na décima aurora dedirrósea/ O interrogou, pedindo-lhe a tabela/ Que lhe fiara Preto. Os caracteres/ Fatais lendo, a Quimera inexpugnável/ Mandou-lhe exterminar: tinha esse monstro,/ De raça divinal que não terrestre,/ A cara de leão, de serpe a cauda,/ Caprino ventre, ignívoma a garganta;/ E ele extinguiu-a por celeste influxo./ Logo os Solimos debelou, façanha/ Que julgava a maior; e enfim deu cabo/ Das Amazonas varonis. (HOMERO, 2008: 155/156)

No entanto, e apesar de serem capazes de se igualar ao homem em suas proezas ${ }^{8}$, os textos literários da antiguidade não abrem espaço para que estas mulheres realizem seus empreendimentos bélicos sem obstáculos e reveses. Sobre o assunto comenta Brunel que:

No seu desejo de igualar-se ao homem, a mulher fracassa vez por outra e se reencontra em conformidade com a natureza que lhe é própria, quando exposta ao perigo. Suas lágrimas trágicas ou suas imprecações de vociferante funcionam nessas horas, ao que parece, como uma arma muito mais eficaz do que todas as lanças do mundo (BRUNEL, 2000: 745).

Assim sendo, o lado mais agressivo das Amazonas era considerado e privilegiado. Nesse sentido, essas figuras podem ser consideradas como mulheres-homens, ou em uma primeira análise mulheres "anti-homens" (BRUNEL, 2000: 745), que procuram por suas ações eliminar o macho ou reduzi-lo a um estado de submissão e docilidade. Até porque não

\footnotetext{
${ }^{8}$ No caso específico as Valquírias germânicas, que realizam todos os gestos que o herói executa, chegando mesmo a ridicularizá-lo.
} 
existe notícia de que essas mulheres combatem entre si, ou que enfrentam outros povoados comandados por mulheres.

Sua posição de lutadoras sempre se desenvolve e se constrói tendo por oponente a figura masculina: e é nesse sentido que elas recusam o casamento, o qual seria por elas encarado como uma forma de sujeição ou submissão. Sobre o assunto, Johnni Langer informa que:

Existem diversas facetas que devem ser destacadas quanto ao aspecto combativo destas mulheres. A primeira é dar ênfase aos poderes mágicos que lhe são concedidos por Odin. Sob a benção de uma valquíria, um guerreiro era completamente protegido de qualquer dano mortal que poderia lhe ser causado durante uma contenda, bem como causar-lhe a derrota e a morte. É válido lembrar que tais dons são providos diretamente por Odin: desobedecer suas ordens implica na punição máxima dada à uma valquíria, o confinamento ao casamento. (LANGER e NEIVA, 2012: 7,8)

Na opinião dos gregos, a Amazona é a expressão mais clara da figura da mulher em relação à animalidade. E à medida que ela se torna uma "matadora de homens", esse princípio mais e mais se consolida. Cabe aqui perguntar como esse macho pode ser aniquilado por elas: primeiramente pela força, obviamente. Em segundo lugar, pela sedução, ou melhor, dito, pela sujeição daquele diante da beleza delas.

Destarte a mulher-homem deixa de possuir essa caracterização para se tornar a mulher de muitos homens, originando a mulher fatal dos romances modernos, tema esse que não conhece ocaso no universo dos estudos literários, e que sempre a coloca em oposição à outra figuração de mulher: a virgem idealmente pura e imaculada, cuja santidade é excepcional e admirável pelas suas frequentes recusas às tentações.

A partir daí tangencia-se o terceiro viés pelo qual o mito das mulheres viris é norteado, qual seja ele, o de que elas poderiam passar por uma “(...) espécie de ideal numa perspectiva de antagonismo entre os sexos: seriam mulheres-sem-homens, ou seja, que teriam encontrado a maneira de não precisar desses incômodos parceiros”. (BRUNEL, 2000: 746). ${ }^{10}$

É notável que, quando as Valquírias consentem em ter um filho, seu status enquanto mulher guerreira está perdido e elas se tornam simples mulheres, mães de reis e servas de guerreiros escolhidos que habitam o Valhala. Sobre o assunto, Boyer informa que:

\footnotetext{
${ }^{9}$ Sobre o assunto ver: WOORTMANN, Klaas. O Selvagem e a História. Heródoto e a questão do Outro. In: Revista de Antropologia. Vol 43, n 1, São Paulo: 2000.

${ }^{10} \mathrm{O}$ grifo acompanha o original.
} 
(...) quando as Valquírias consentem em ter um filho, perdem ipso facto seu status e se tornam simples mulheres, se assim se pode dizer, servas de guerreiros escolhidos da Válala [sic] e mais de príncipes. Como se houvesse incompatibilidade entre a mulher-cisne intocável ou a virgem com o elmo na cabeça, e a senhora da cerveja (Ölrun) (BOYER, apud, LANGER, 2004: 63).

Nesse caso, a figura da mulher que se recusa a aceitar os homens a não ser pela perpetuação da espécie é um elemento mítico que reencontra hoje muitas tessituras as quais atestam a vitalidade deste elemento, deixando muito claro que tal premissa atua sobre o aspecto de uma complementaridade que seria necessária aos dois sexos.

É a partir dessas premissas que o presente artigo iniciará doravante as suas análises em relação a personagem Luzia, apontando nela as questões que referendam estes aspectos brevemente discutidos e que a associam ao monstruoso, buscando definir os contornos que entrelaçam essas duas vertentes.

\section{O romance}

Cabe situar os leitores e leitoras no ambiente do romance para melhor serem entendidas as ilações que este artigo pretende realizar: Domingos Olímpio é um autor cearense, nascido em Sobral no século $\mathrm{XIX}^{11}$. Sua obra Luzia-Homem é sem dúvida, o romance que o tornou conhecido sendo reeditada até os dias de hoje. Nela, Olímpio narra o drama das secas que assolam a região, bem como as migrações internas realizadas pelos nordestinos que buscavam nas cidades próximas ao literal melhores condições de vida.

No entanto, fica muito claro que essa população acabava sendo explorada e que a política do período se aproveitava da condição de aviltamento em que viviam esses homens e mulheres, condições essas que seriam análogas as da escravidão, e que se eivavam de elementos referentes a assédio moral e sexual, violência policial, desagregação do núcleo familiar e desespero frente a luta cotidiana pela sobrevivência e em busca de um futuro mais feliz. Numa breve síntese, o romance trata destas polêmicas questões.

Esse quadro de pungente sofrimento traz em si o surgimento de uma ideia de mal e de sofrimento, berço profícuo para a criação dos monstros. Sobre o mal, Julio Jeha, diz o seguinte:

\footnotetext{
${ }^{11}$ Ele nasceu em 18 de setembro de 1851.
} 
Em princípio, uma abordagem secular do mal deve evitar considerações religiosas, mas isso diminuiria os méritos do argumento. Como a tradição cristã moldou e informou o desenvolvimento da nossa civilização, com tudo o que isso possa acarretar, qualquer análise do mal deve levar em conta a caracterização católica deste fenômeno. A escolha, então, se determina pela continuidade desde o início da Igreja Católica e o debate filosófico que ela ensejou. Se deixarmos de lado referências ao sobrenatural, é possível explorar e examinar as especulações teológicas e filosóficas que animaram a igreja primitiva e transportar essa análise do mal para a literatura (JEHA, 2007: 12)

As duas respostas mais comuns ao mal vem da moral e da sabedoria. A primeira vê os seres humanos na forma de agentes conscientes do mal; a segunda os caracteriza como ameaças a autoidentidade. Pelo viés da moralidade o mal é qualquer obstáculo que impede um ser de alcançar a perfeição. Pelo viés da sabedoria, o mal é a qualidade frustrada de um desejo não satisfeito.

A moralidade foca sua ideia de mal nas ações, a sabedoria, no conhecimento. Mas ambas concordam que o mal é o oposto do bem, sendo o bem entendido como a integridade do ser, daí a necessidade de combater o mal. No caso do romance de Olímpio, o arquétipo do mal que mais se levanta inexorável é o que advém da moralidade.

No contexto da obra, destaca-se a personagem Luzia ${ }^{12}$ que desde a primeira aparição no romance já prefigura a questão do monstruoso como elemento marcante da sua presença, bem entendida essa questão como sendo o seu aspecto masculinizado, o qual traz em si inerente a sua força bruta, comparável a de um homem:

Viram-na outros levar, firme, sobre a cabeça, uma enorme jarra d'água, que
valia três potes, de peso calculado para a força normal de um homem
robusto. De outra feita, removera e assentara no lugar próprio, a soleira de
granito da porta principal da prisão, causando pasmo aos mais valentes
operários, que haviam tentado em vão, a façanha e com eles, Raulino Uchoa,
sertanejo hercúleo e afamado, prodigioso de destreza, que chibanteava em
pitorescas narrativas. (OLÍMPIO, 2008: 3 )

Chama a atenção aqui o fato de que para um homem robusto, carregar aquela jarra de água na cabeça era um feito normal. Como quem carregava a água era Luzia, fica evidente a desproporção da sua força descomunal, ou seja, ela rompe com uma fronteira que é inerente a sua condição de mulher, ou pelo menos deveria ser. Nesse sentido Butler interroga essa inerência ao analisar o sexo como resultado discursivo/cultural e não como algo

${ }^{12}$ O nome Luzia tem origem no grego e significa a iluminada, podendo também ser entendido como a luminosa. 
constituído antes do discurso e da cultura. Em suas discussões Judith Butler aborda gênero como uma categoria temporária e performativa abrindo perspectiva para a desnaturalização das práticas de significação como, por exemplo, de que gênero está para a cultura e sexo está para a natureza. Seguindo a perspectiva de Foucault, Butler analisa o efeito discursivo de gênero e assim entende que o sexo é um efeito de gênero. Observa a autora que:

Se o sexo é, ele próprio, uma categoria tomada em seu gênero, não faz sentido definir o gênero como a interpretação cultural do sexo. O gênero não deve ser concebido como a inscrição cultural de significado num sexo previamente dado (uma concepção jurídica; tem de designar também o aparato mesmo de produção mediante o qual os próprios sexos são estabelecidos) (BUTLER, 2003: 15).

Destarte, nomear a condição da mulher implica em determinar uma natureza para o gênero feminino. A exclusão pode ser entendida como parte de um disciplinamento obrigatório e destino para todas as mulheres, ou seja, a maternidade, a submissão, o recato, a docilidade, a resignação. Assim, há toda uma leitura do social na qual a natureza constitui-se numa ética disciplinatória. A identidade para as mulheres é somente um ideal normativo que se vincula a noção de natureza e é fixa para toda a vida como uma essência.

Em relação à naturalização do feminino na literatura, Butler (2003) observa que comportamentos não esperados para o corpo feminino geralmente são punidos. São estes comportamentos que podem por em questão o ideal normativo e sua suposta natureza. Novamente convêm reforçar que esta natureza prescreve um deve ser implícito. ${ }^{13}$

Assim, os mandatos sociais que recaem sobre o corpo feminino soam muito mais fortes do que sobre o dos homens. Daí que a construção de disciplinamentos encobre a noção de natureza, a exemplo a quantidade de vezes que as mulheres são consideradas mães desnaturadas ao abandonarem um filho, mas o mesmo não ocorre em relação à paternidade. ${ }^{14}$

A noção de natureza é uma construção, um mandato, uma prescrição que implica em uma escala de valores de acordo com a estrutura social de uma época como se observa neste excerto:“(...) nem parece mulher fêmea (...) (OLÍMPIO, 2008: 3), pois ela tinha “(...) cabelos nos braços e um buço que parece bigode de homem" (OLíMPIO, 2008: 3). Com isso o narrador apresenta por algumas vezes sua caracterização física masculinizante, ou seja, o

\footnotetext{
${ }^{13}$ Veja-se artigo ZIMMERMANN, Tânia. Relações de gênero e situações de violência no romance "O Cortiço", de Aloísio Azevedo. In: Revista Cordis: Revista Eletrônica de História Social da Cidade www.pucsp.br/revistacordis

14 Idem, ibidem.
} 
bigode. O uso do bigode, em determinado período histórico, também tem relação com o corpo masculinizado.

O bigode é definido como "barba que nasce sobre o lábio superior" ${ }^{15}$, ou seja, um conjunto de pelos faciais localizados abaixo do nariz e acima dos lábios superiores e não tem indicativo de gênero, porque mulheres e homens podem ser dotados destes pelos com maior ou menor visibilidade. Assim, o pelo não é apenas um signo biológico e sim cultural. A pilosidade tem uma dimensão política porque transmite um signo de poder. Capriuna em sua descrição física não dista desta tendência em determinado período aqui no Brasil: "o bigode teso e fino como um espeto". Assim, o bigode é um símbolo da masculinidade hegemônica positivada reproduzida em Crapiuna, mas não em Luzia.

Neste romance, as situações criadas pelo meio social de pobreza e a luta pela sobrevivência ampliaram as diferenças entre os gêneros e deviam ser constantemente reforçadas. No entanto, Luzia poderia ser uma exceção em seu gênero e, portanto, possuidora de comportamento passível de ser estereotipado como masculino, como por exemplo, através do buço.

O bigode é segundo Gil Mihaely um signo biológico, sobre o qual se assentaram diferenças culturais, ou seja, um discurso médico-científico desde o final do século XVIII, sobre a pilosidade. Este autor destaca que:

[...] e era interessante ver como um discurso científico, médico, cruza um imaginário que se tece em torno dos militares, pois, ao mesmo tempo, acontece a apologia da ascensão dos militares, cujos primeiros signos estavam esboçados um século antes, senão mais. As guerras revolucionárias, o Império, foram o coroamento dos militares, e é nesse momento também que se dá no exército a propagação do bigode. Eu penso que isso se deveu a uma dinâmica de concorrência entre os militares. No século XVIII, com efeito, o bigode tornou-se o atributo das unidades de elite, e na economia simbólica do exército os atributos das unidades de elite eram muito valorizados e invejados, o que criou uma dinâmica de imitação. Essa não é, evidentemente, a única razão, e, além disso, é artificial separar o exército da sociedade: as mesmas imagens circulavam no exército e na sociedade civil. (WOLFF, 2007: 226)

A ascensão dos militares franceses após o século XVIII se junta com a imagem de virilidade através do uso do bigode. Esse modelo de masculinidade torna-se hegemônico e estará presente nas mais diferentes atividades artísticas. Sobre esse modelo Mihaely complementa:

\footnotetext{
${ }^{15}$ Esta definição encontra-se em verbete do seguinte dicionário: ANJOS, Margarida; FERREIRA, Marina B.; FERREIRA, Elza T.; MARQUES, Joaquim C. Dicionário Aurélio. Rio de Janeiro : Nova Fronteira, 1988.
} 
Desde os primeiros anos da Restauração, encontramos casos de imitação consciente dos militares. Esse é um ponto muito importante, pois para existir um modelo hegemônico, é preciso que haja pessoas que acreditem que é um modelo hegemônico. Encontrei exemplos de pessoas que atribuíram por seu consentimento, mais ou menos consciente, o status de virilidade, de masculinidade hegemônica, aos militares e aos atributos que estavam associados com os militares. Esse status ultrapassava as clivagens e os conflitos políticos e sociais da época (WOLFF, 2007: 226)

Assim, pelo fato de Crapiúna ser soldado e possuidor de bigode muitas pessoas acreditavam que ele constituía o modelo hegemônico de masculinidade e, portanto apto a dominar as mulheres pela sedução ou pela força.

Ademais, outra passagem do romance faz a ligação direta de Luzia com a figura das Amazonas comentada na primeira parte deste artigo, quando Crapiúna, um soldado que faz várias investidas de cunho sexual sobre Luzia, não se conforma com “(...) os modos retraídos e a impassível frieza da mulher-homem (...) ${ }^{16 ", ~(O L I ́ M P I O, ~ 2008: ~ 4) . ~}$

Assim sendo, Luzia constitui-se como uma pedra no meio do caminho do conhecido conquistador que é o soldado, e certamente como uma maravilha que quebra o protocolo linear estabelecido entre aquela gente pobre. Ela resiste às investidas e nega o que Crapiúna deseja, mesmo que ele tente comprá-la com presentes e agrados. Outras moças condenadas pela miséria e cheias de desespero podem ceder a ele, porém, não Luzia.

Luzia demonstra ser capaz de transgredir o limite que a miséria impõe sobre as demais pessoas que convivem ao seu redor, e no caso do romance, aquela que não se aviltava, que não se vendia, que não se entregava é que acaba sendo o monstro transgressor das fronteiras e das normas impostas pelo grupo. Sua presença e sua ação, sua forma física, sua força desmedida causam desconforto e nesse sentido ela se enquadra dentro da linha do pensamento sobre monstros definida por Julia Jeha:

Qualquer transgressão das fronteiras ou limites estabelecidos pelo grupo, quer sejam abstratos ou concretos, causa desconforto e requer que o mundo retorne ao estado considerado certo. O monstro é um artifício pra rotular as infrações desses limites sociais (JEHA, 2009:20)

A experiência humana tem base no conhecimento e na projeção do ser que os indivíduos constituem: mudanças em qualquer uma dessas vias geram alterações na percepção

\footnotetext{
${ }^{16} \mathrm{O}$ grifo não acompanha o original.
} 
de realidade, possíveis acréscimos que obrigam a expandir horizontes. Quando isso acontece, as expectativas de ordenamento e as fronteiras são rompidas e é nessa zona de transgressão que o monstro é gerado. Mostro que (como Luzia) não se enquadra nos limites confortáveis do conhecido.

Em outras passagens do romance Luzia é descrita como "macho e fêmea" (OLÍMPIO, 2008, p. 5), figura que possui tanta força que "nem parece mulher" (OLÍMPIO, 2008: 5) e "monstro da natureza" (OLÍMPIO, 2008: 6). Essas passagens denotam que sua figura revela o avesso da concepção de real que se possui em relação às mulheres (da mesma forma como as Amazonas representam um avesso), apontando um desencontro no que tange a essa categoria.

Vista por esse prisma a personagem Luzia poderia ser tida por um aviso de que algo deve ser mudado ou refeito devido a sua presença, ou mesmo como um castigo devido à transgressão de uma norma de conduta, ou um código. No caso do romance de Olímpio, Luzia pode ser entendida de acordo com a segunda hipótese, conforme a própria fala da personagem referenda: “(...). Imagine a briga de dois homens, pancadas, ferimentos, um crime e meu nome detestado passando de boca em boca, Luzia-Homem causadora de tudo..." (OLÍMPIO, 2008: $7)^{17}$.

Na sua condição de "monstro", representante deste arquétipo transgressor, devido à sua força física e a sua conduta, Luzia é deixada no ostracismo por parte das outras moças, conforme se aufere da citação abaixo transcrita:

As moças da mesma idade, ainda não contaminadas pelo vírus pecaminoso, que empestava o ambiente, evitavam-na com maneiras tímidas, discreto acanhamento, como se não fossem iguais na condição e infortúnio. Muitas se afastavam dela, da orgulhosa e seca Luzia-Homem com secreto terror, e lhe faziam a furto figas e cruzes. Mulher que tinha buço de rapaz, pernas e braços forrados de pelúcia crespa e entonos de força, com ares varonis, uma virago, avessa a homens, devera ser um desses erros da natureza, marcados com o estigma dos desvios monstruosos do ventre que os concebera. (OLÍMPIO, 2008: 8,9)

A parte a citação comprovar de forma clara a representação de Luzia como uma mulher viril, ela marca claramente o lugar que ela deve ocupar no contexto social que a cerca, pois o monstro ou a ideia que circunda o termo é sempre utilizada como referência a todo ser que "morfológica ou culturalmente se distinga das normas estéticas ou éticas vigentes" (MAGALHÃES, 2003: 26).

${ }^{17} \mathrm{O}$ grifo não acompanha o original. 
A ideia aqui proposta acaba por aproximar o monstro do selvagem ou do não civilizado de acordo com determinado padrão cultural, deixando claro que a monstruosidade não existe a não ser quando relacionada a uma ordem estabelecida, ou a uma cultura, sendo, portanto a identidade do outro que afronta (assombra) determinado grupo.

Mas a mesma Luzia que assume esse arquétipo é também a que se apresenta aos olhos dos leitores e leitoras de Olímpio como se fosse um anjo, pois graças a sua força descomunal ela salvou um colega de infortúnio das garras da morte:

Eu tomei por soberba. Cem anos que viva, terei sempre diante dos olhos e do pensamento, a sua figura, de cabelos soltos, rompendo a multidão, com o Raulino nos braços, como se fora uma criança. Lembrava-me um registro do Anjo da Guarda, levando a alma de um inocente par ao céu. (Olímpio, 2008:13)

É preciso lembrar que os anjos bíblicos também podem ser monstruosos e com sua resplandecência divina causar medo aos reles mortais, basta para isso lembrar de que Adão sentiu medo diante da presença divina depois de provar da Árvore do Conhecimento e por isso se escondeu dos olhos de Deus ${ }^{18}$ e Sara, esposa de Abrão também teve medo do anjo que anunciou sua futura gravidez, por haver rido desse fato ${ }^{19}$. Destarte, mesmo quando remete a figura divina, a representação de Luzia traz em si intrínseco o sentimento de medo que acompanha a presença do monstro, ou melhor dito, daquilo que foge ao que o senso de compreensão humano chama de natural.

\section{Considerações finais}

Assim, a personagem construída por Olímpio beira as reminiscências do monstro do período renascentista: aquele (ou aquela) que nasce dos desígnios divinos sejam eles do bem (Deus) ou do mal (Diabo); o ente que pode ser resultado de uma conjunção astral; ou ainda da “cópula humana com outras espécies ou dos defeitos de anatomia dos genitores" (MAGALHÃES, 2003: 24).

Independente do processo, o monstro sempre está posto lado a lado com a abominação, com o desarranjo entre pai e filho, prenunciando a desordem e o caos. Assim, ele vem a ser uma mensagem de Deus, que nele deixa clara toda a sua ira, sua presença apenas

\footnotetext{
${ }^{18}$ Bíblia Sagrada, Gênesis 3:10.

${ }^{19}$ Bíblia Sagrada, Gênesis 18:15.
} 
mostra os desastres futuros que poderão advir. Nesse sentido, as assertivas de Foucault discutidas no contexto contemporâneo inspiram análises sobre o tema aqui discutido, ou seja, o monstro é o modelo de todas as discrepâncias e “[...] é o princípio da inteligibilidade de todas as formas - que circulam na forma de moeda miúda - da anomalia." (FOUCAULT, 2002, p.71-72) Este autor ainda observa que "Ele é, num registro duplo, infração as leis em sua existência mesma." Neste sentido, as Amazonas e posteriormente Luzia aparecem como um fenômeno raro e extremo que combina o impossível com o proibido. "[...] é o grande modelo de todas as pequenas discrepâncias" (FOUCAULT, 2002, p. 69-71). O monstro deve desaparecer porque ele prenuncia o caos e o mundo só restabelece a ordem se ele desaparecer.

O destino de Luzia se assemelha ao das Amazonas, mulheres viris que desaparecem, pois, assim como ela, invertem a ordem natural e por isso rompem com as fronteiras do dito "natural" necessitando, portanto seu fim para que o mundo retorne a ordem e do caos se faça novamente a luz.

\section{Referências Bibliográficas}

ANJOS, Margarida (et AL). Dicionário Aurélio. Rio de Janeiro: Nova Fronteira, 1988.

BÍBLIA Sagrada. 2 ed., Barueri: Sociedade Bíblica do Brasil, 1993.

BUTLER, Judith. Problemas de Gênero: feminismo e subversão da identidade. Rio de Janeiro: Civilização Brasileira, 2003.

BRUNEL, Pierre. Dicionário de Mitos Literários. 3 ed., Rio de Janeiro: José Olympio, 2000.

DHOQUAIS, R. O Direito do Trabalho e o corpo da mulher (França: séculos XIX e XX). In: MATOS, Maria Izilda S. de; SOIHET, Rachel. O Corpo Feminino em Debate. São Paulo: UNESP, 2003.

ELIAS, Norbert. Über den Prozeß der Zivilization. Soziogenetische und psychogenetische Untersuchungen. Bd. 1: Wandlungen des Verhaltens in den weltlichen Oberschichten des Abendlandes. 20 Aufl. Frankfurt am Main: Suhrkamp, 1997.

GRAVES, Robert. O Grande Livro dos Mitos Gregos. São Paulo: Ediouro, 2008.

LAQUEUR, Thomas. Inventando o Sexo: corpo e gênero dos gregos a Freud. Rio de Janeiro :RelumeDumara, 2001 ,

FOUCAULT, M. Os Anormais. São Paulo: Martins Fontes, 2002.

HOMERO. Ilíada. São Paulo/Campinas: Ateliê Editorial/UNICAMP, 2008.

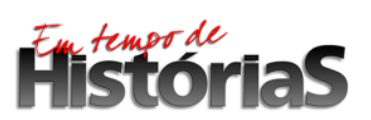

(PPGHIS/UnB) №. 25, Brasília, Ago- Dez 2015 ISSN 2316-1191 
JEHA, Júlio. Das origens do mal: a curiosidade em Frankenstein. In: JEHA, Júlio e NASCIMENTO, Lisley (org). Da fabricação de monstros. Belo Horizonte: Editora da UFMG, 2009.

Monstros como metáforas do mal. In: JEHA, Júlio (org). Monstros e monstruosidades na literatura. Belo Horizonte: Editora da UFMG, 2007.

JUNG, Carl Gustav.Os Arquétipos e o Inconsciente Coletivo. Petrópolis: Vozes, 2011.

LANGER, Johnni. Guerreiras de Odinn: As Valkyrjor na Mitologia Viking. In: Revista Brathair, n 4, vol 1, 2004, p. 52-69.

LANGER, Johnni e NEIVA, Weber. Valquírias Versus Gigantas: Modelos Marciais Femininos na Literatura Escandinava. In: Revista Brasileira de História das Religiões, n. 13, 2012.

MAGALHÃES, Célia. Os monstros e a questão racial na narrativa modernista brasileira. Belo Horizonte: UFMG, 2003.

OLIMPIO, Domingos. Luzia-Homem. São Paulo; Moderna, 2008.

SCOTT, Joan, Gênero: uma categoria útil de análise histórica. In: Educação e Realidade. Porto Alegre, n. 16, julho/dezembro, 1990, p. 7-14.

WOLFF, Cristina Scheibe. Gênero, masculinidade e militarismo: uma entrevista com o historiador Gil Mihaely. Revista Esboços. Florianópolis: UFSC, v. 14, n. 17, 2007, p. 221-233.

WOORTMANN, Klaas. O Selvagem e a História. Heródoto e a questão do Outro. In: Revista de Antropologia. Vol 43, n 1, São Paulo, 2000, p. 13-59.

ZIMMERMANN, Tânia. Relações de gênero e situações de violência no romance "O Cortiço", de Aloísio Azevedo. In: Revista Cordis: Revista Eletrônica de História Social da Cidade www.pucsp.br/revistacordis. 